\title{
Correlation Study on Undergraduates' Internet Altruistic Behavior, Self-Concept and Inter-Personal Relation
}

\author{
Huiying Liu, Xueke Huang*, Bian Du, Pan Wu \\ Education Department of Zhengzhou University, Zhengzhou, China \\ Email: liuhy@zzu.edu.cn, ${ }^{*}$ huangxuekeyouxiang@126.com, dubiango@163.com, 897305277@qq.com
}

Received 4 February 2014; revised 4 March 2014; accepted 11 March 2014

Copyright (C) 2014 by authors and Scientific Research Publishing Inc.

This work is licensed under the Creative Commons Attribution International License (CC BY).

http://creativecommons.org/licenses/by/4.0/

(c) (i) Open Access

\begin{abstract}
Purposes: To study the relation among self-concept, inter-personal relation and internet altruistic behavior. Methods: Adopt internet altruistic behavior scale, TSCS, inter-personal relation scale to test 177 in-school undergraduates. Results: Difference of total score of internet altruistic behavior and its factor scores in students of different genders, grades and only child and child with siblings is not significant $(p>.05)$. There are differences in major among dimensions of internet sharing and internet guidance $(p<.05)$; and the scores of art students are higher than those of engineering students; psychological self has a significant correlation with internet supporting; social self has a significant correlation with total scores of internet altruistic behavior, internet supporting and internet reminding, but the total scores of self-concept have no significant correlation with the total scores of internet altruistic behavior and its factor scores. Internet altruistic behavior has a significant correlation with inter-personal relation.
\end{abstract}

\section{Keywords}

Internet Altruistic Behavior, Self Concept, Inter-Personal Relation, Undergraduates

\section{Introduction}

According to China Internet Network Development State Statistic Report No. 32 published by China Internet Network Information Centre (CNNIC), till the end of June, 2013, the population of net citizen has reached 591 million with students accounting for $26.8 \%$ of the whole. The internet has had greater and greater influence to-

${ }^{*}$ Corresponding author.

How to cite this paper: Liu, H. Y., Huang, X. K., Du, B., \& Wu, P. (2014). Correlation Study on Undergraduates' Internet Altruistic Behavior, Self-Concept and Inter-Personal Relation. Advances in Applied Sociology, 4, 128-133.

http://dx.doi.org/10.4236/aasoci.2014.44016 
wards the behavioral pattern, value orientation, political attitude and moral sense and other aspects of undergraduates. A major part of inter-personal relation has been transferred to the internet. Besides being the tool for people to have access to information, the internet has also become an important place where people seek friendship, sense of belonging and emotional support and an important way for people to get help.

Altruistic behavior is put forward by French sociologist A. Comte which is used to express individual's selfless behavior to the others (Zhang Zhiguang, 1996). Altruistic behavior is a high-level prosocial behavior, the motive of which is voluntary; the actor does not help others to get material or social reward, instead, the actor does this to promote the happiness of others and to benefit others. Internet altruistic behavior means the voluntary behavior happening in the internet environment which meets the social expectation and is beneficial to others, groups or the society without expectation of return or reward in any form (Peng Qinghong \& Fan Fumin, 2005). With the socialization of the internet, internet altruistic behavior is more than helping behavior in real life. (Pahiciawallace, 2001). Karabenick and others study that, as compared with those besides, people prefer to ask the computer for help. For altruistic behavior, speed and scope of spreading in internet have surpassed the real society (Zhao Huanhuan, 2012). Frequency of occurrence of altruistic behavior in the internet environment is higher than that in the real life (Guo Yujin, 2005).

Discussions on altruistic behavior theory are related to self factors. Research theories of altruistic behavior include motivation theory (Batson \& Powell, 2003), evolution theory (Sober, 1988), social exchange theory (Homans,) and so on. All of these theories contain arguments related to self concept. For example, Batson thinks that altruism is divided into ego altruism and pure altruism. When an altruist finds others in trouble, he will focus on his own anxiety, and in order to reduce the anxiety, he will take altruistic actions, which is a kind of ego altruism for the purpose of serving himself. If the person focuses on sympathizing others and the purpose of his behavior is to reduce others' suffering, then this is pure altruism (Tu Wenshu, 2001). Cali Rawski, another supporter of motivation theory, thinks that there is a kind of altruism pointing to individual's inner world, which is used to positively maintain and improve self image for individuals and is called introversive altruism (Shi Ronghua, 2001). Sober, a scholar of evolution also divides altruism into two categories: the evolved altruism and the local altruism. The former one is the unconscious behavior of an individual during an emergency and the individual person regards people in trouble as a part of himself, while the latter one is the behavior of an individual triggered by the motivation of benefiting others (Sober, 1988). Homans, a scholar of social exchange theory believes that: for an altruist, it seems that there is only giving but no receiving, but in fact it is a benefit of introversive reward and the compliment and satisfaction of him after implementing altruistic behavior, which brings him happiness (Lu Haidong, 2002). Characteristics of recipients, social and cultural characteristics, the situational factors of altruistic behaviors, self factors of altruists all are subjective and objective factors affecting altruistic behaviors, and the age, gender, religion, personality, cognition, emotion and so on of altruists have a significant impact on altruistic behaviors.

Research is correlated between self concept and altruistic behavior. Self concept refers to the individual's consciousness to himself and is the self-cognition and self-evaluation of his own physical and mental characteristics (Halesowen, 1976). Self concept is the core part of the personality structure, and people's self-cognition may directly affect their individual behaviors. If a person thinks himself is benevolent, then he will naturally keep himself doing nice things; if he believes he helps others only for getting rewards or avoiding threats, he may also choose not to offer help in many cases where people may need help, which means self concept influences the helping behavior (altruism) (Hou Jiliang, 1991). Many scholars also believe that there are certain relations between personality traits and altruistic behaviors, that is, a kind of altruistic personality exists. According to the personality questionnaire, the altruism indexes positively correlate with helping behaviors of certain situations (Rushton, 1980; Staub, 1986). Li Yanfang, a scholar, points out that altruistic behaviors are significantly associated with self concept (Li Yanfang, 2008). The self concept of undergraduates directly influences their altruistic behaviors which can also be indirectly influenced by their moral values. The standardized regression equation of the optimal regression model on the undergraduate's altruistic behavior level is as follows: undergraduate's altruistic behavior level $=1.170+.383 \times$ average score of self-interest $+.268 \times$ average score of personal virtue $+.261 \times$ average score of morality $+.098 \times$ average score of self concept (Li Yanfang, 2008).

Researches on interpersonal relationship are related to altruistic behavior. Interpersonal relationship is people's directly psychological relations or distances during their interaction. Every individual in the social life has a relationship with others. Interpersonal relationship is the result of the interaction between one individual and 
another in the society, reflecting their mental state of seeking for their social needs. Roles of close relations such as close relatives and close friends can make people show their altruism such as magnanimous, generous and giving (Wei Xiangfeng, 2006). Scholars' researches prove that altruistic behavior has a significantly negative correlation with troubled interpersonal relationship, which means the lower the altruistic behavior level is, the higher the degree of interpersonal problem is (Xue Deyu, 2011). Interpersonal trust, as a positive belief of interpersonal relationships, to some extent, is on behalf of its altruism orientation (Staub, E., 1994). With the increase of the interpersonal trust level, individuals tend to choose the common goal or behaviors generating the common interests (Van Lange, P.A.M., 1998), with prosocial behavior accordingly increasing (Cadenhead \& Richman, 1996).

To sum up, self concept and interpersonal relationship are closely related to the real altruistic behavior, but how about their relations with internet altruistic behavior? Current exploration for internet altruistic behavior is still in its infancy, poor in empirical researches. Therefore, it is necessary to focus on and research the relation between internet altruistic behavior and self concept, and that between internet altruistic behavior and interpersonal relationship for the development of internet society. This research puts forward the following two assumptions based on predecessors' researches:

1) Factors of self concept have a significant correlation with internet altruistic behavior.

2) Good interpersonal relationship has a significantly positive correlation with the internet altruistic behavior.

\section{Research Object and Methods}

\subsection{Research Object}

The research adopts handy sampling. Questionnaires were handed out in two universities' libraries in Zhengzhou with pens as gifts, and were collected timely after being finished. There were total 177 undergraduates filling out the questionnaires, with 156 effective questionnaires collected. Distribution of the subjects is: 84 male students, 72 female students; 75 freshmen, 39 sophomores, 42 juniors; 48 only-child, 108 students with siblings.

\subsection{Research Tool}

\subsubsection{Internet Altruistic Behavior}

Adopt IABSU prepared by Zheng Xianliang in year 2010, with a total of 26 items of the scale, including four dimensions of internet support, internet guidance, internet sharing and internet reminding. The scale is scoring in 4 points ("Never" is 1, "Always" is 4). The higher the test scores are, the greater degree its internet altruistic behavior is. Relevant research shows that, $\alpha$ factor of IABSU general scale is .937; $\alpha$ factors of different dimensions are in the range of $.800-.878$; this indicates that IABSU has a high-level intrinsic consistency.

\subsubsection{Scale of Self Concept}

By adopting TSCS revised by Lin Bangjie, this scale is prepared by American Psychologist Fitts with a total of 70 test subjects, which are divided into general condition (self-scoring, self-criticism), content dimension (physical self, moral-ethical self, psychological self, family self, social self) and structure dimension (self-identification, self-satisfaction and self-action). Adopt five ratings, with good reliability and validity.

\subsubsection{Questionaire for Inter-Personal Relation among Undergraduates}

Questionaire for Inter-Personal Relation among Undergraduates is prepared by Wudan in year 2007 and this scale is divided into four dimensions of inter-personal relation between teachers and students, inter-personal relation among schoolmates, inter-personal relation in life and virtual inter-personal relation. The questionnaire adopts evaluation in five levels. Reliability and validity conform to the psychometrics standard.

\subsection{Testing Program and Data Processing}

This study adopts two methods of collective and individual testing, with part of the questionnaires used for testing based on classes and part of those issued to those in self study room for easy sampling. The questionnaires shall be filled anonymously. Enter all effective data that have been selected into the computer; compile and analyze the data using statistical software Spss16.0; statistical methods used mainly include descriptive statistics, $\mathrm{t}$ 
test, variance analysis and correlation analysis.

\section{Results}

\subsection{Characteristics of Internet Altruistic Behavior among Undergraduates}

Results of variance analysis in demographic variables show that difference of total scores of internet altruistic behavior and its factor scores in students of different genders, grades and only child and child with siblings is not significant ( $>$.05) (as shown in Table 1). The dimensions of internet sharing and internet guidance have great difference in the sense of major $(\mathrm{p}<.05)$; and the scores of arts students are higher than those of engineering students.

\subsection{Correlation of Self Concept and Internet Altruistic Behavior}

In order to study the relation between self concept and internet altruistic behavior, we will conduct relevant analysis towards them. It can be seen from Table 2 that the total scores of self concept have no significant correlation with the total scores of internet altruistic behavior ( $p>.05$ ). Further observation of the correlation of different dimensions reveals that social self has significant correlation with total scores of internet altruistic behavior $(\mathrm{p}<.05)$, internet supporting factor score $(\mathrm{p}<.01)$, internet reminding factor score $(\mathrm{p}<.01)$; and psychological self has significant correlation with score of internet supporting factor $(\mathrm{p}<.05)$.

\subsection{Correlation of Inter-Personal Relationship and Internet Altruistic Behavior}

Analysis results of interpersonal relation and internet altruistic behavior show that total scores of inter-personal relation has significant correlation with total scores of internet altruistic behavior $(\mathrm{p}<.01)$ (as shown in Table 3). Further observation of the correlation of different dimensions reveals that the dimension of inter-personal relation between students has no significant correlation with total scores of internet altruistic behavior or factor scores $(\mathrm{p}>.05)$; the dimension of internet sharing has no significant correlation with total scores of interpersonal relationship and its factor scores $(\mathrm{p}>.05)$ and has significant correlation with other factor scores $(\mathrm{p}<.05)$.

Table 1. Characteristics of internet altruistic behavior among undergraduates.

\begin{tabular}{ccccc}
\hline & Minimum value & Maximum value & Average value & Standard deviation \\
\hline Total score of internet altruistic behavior & 26 & 104 & 57.058 & 15.349 \\
Internet sharing & 6 & 24 & 11.923 & 3.783 \\
Internet supporting & 9 & 36 & 22.212 & 6.063 \\
Internet reminding & 5 & 20 & 10.7308 & 3.652 \\
Internet guidance & 6 & 24 & 12.1346 & 4.001 \\
\hline
\end{tabular}

Table 2. Correlation of self concept and internet altruistic behaviour.

\begin{tabular}{|c|c|c|c|c|c|}
\hline & $\begin{array}{c}\text { Total scores of internet } \\
\text { altruistic behavior }\end{array}$ & $\begin{array}{l}\text { Internet } \\
\text { sharing }\end{array}$ & $\begin{array}{c}\text { Internet } \\
\text { supporting }\end{array}$ & $\begin{array}{l}\text { Internet } \\
\text { reminding }\end{array}$ & Internet guidance \\
\hline $\begin{array}{c}\text { Total scores of self } \\
\text { concept }\end{array}$ & .177 & -.033 & .252 & .187 & .105 \\
\hline Physiology self & .028 & -.145 & .03 & .038 & -.54 \\
\hline Morality and ethics self & .137 & .019 & .174 & .166 & .064 \\
\hline Psychological self & .238 & .07 & $.291^{*}$ & .166 & .214 \\
\hline Family self & .069 & -.84 & .161 & .043 & .012 \\
\hline Social self & $.326^{*}$ & .063 & $.357^{* *}$ & $.408^{* *}$ & .209 \\
\hline Self-criticism & .111 & .004 & .159 & .011 & .083 \\
\hline Self-identification & .101 & .004 & .207 & .093 & .083 \\
\hline Self-satisfaction & .171 & -.08 & .215 & .244 & .052 \\
\hline Self-action & .212 & -.006 & .263 & .197 & .047 \\
\hline
\end{tabular}

Note: ${ }^{*}$ represents significant correlation at .05 level (bilaterally) and ${ }^{* *}$ represents significant correlation at .01 level (bilaterally). 
Table 3. Correlation analysis concerning internet altruistic behavior and interpersonal relationship (r).

\begin{tabular}{cccccc}
\hline & $\begin{array}{c}\text { Total scores of } \\
\text { inter-personal relation }\end{array}$ & $\begin{array}{c}\text { Fictitious } \\
\text { inter-personal } \\
\text { relation }\end{array}$ & $\begin{array}{c}\text { Interpersonal } \\
\text { relationship between } \\
\text { teacher and students }\end{array}$ & $\begin{array}{c}\text { Life inter-personal } \\
\text { relation }\end{array}$ & $\begin{array}{c}\text { Inter-personal } \\
\text { relation between } \\
\text { students }\end{array}$ \\
\hline $\begin{array}{c}\text { Total scores of internet } \\
\text { altruistic behavior }\end{array}$ & $.408^{* *}$ & $.372^{* *}$ & $.468^{* *}$ & $.322^{* *}$ & .092 \\
Internet sharing & .248 & .244 & .304 & .155 & .069 \\
Internet supporting & $.383^{* *}$ & $.373^{* *}$ & $.405^{* *}$ & $.291^{*}$ & .104 \\
Internet reminding & $.462^{* *}$ & $.400^{* *}$ & $.522^{* *}$ & $.380^{* *}$ & .112 \\
Internet guidance & $.319^{*}$ & .237 & $.371^{* *}$ & $.296^{*}$ & .067 \\
\hline
\end{tabular}

Note: ${ }^{*}$ represents significant correlation at .05 level (bilaterally) and ${ }^{* *}$ represents significant correlation at .01 level (bilaterally).

\section{Discussion}

There is no great difference of internet altruistic behavior in students of different genders, grades and only child and child with siblings, which might be because the number of samples is small. However, the dimensions of internet sharing and internet guidance have great difference in the sense of major; and the scores of arts students are higher than that of engineering students. Some research shows that internet morality of teenagers is seldom affected by gender or grade (Lei Li \& Ma Xiaohui, 2009); altruistic behaviors of arts students are more than those of engineering students (Li Yanfang, 2008). This study results are in compliance with previous ones.

Results of correlation analysis concerning self concept and internet altruistic behavior show that, psychological self has significant correlation with the score of internet supporting factor; social self has significant correlation with total scores of internet altruistic behavior, internet supporting and internet reminding factor scores; the total scores of internet altruistic behavior and its factor score have correlation with the total scores of self concept; however it is not significant. The research of Liu Zhijun also shows that the social self has significant positive correlation with prosocial behavior and social self can produce positive prediction effect for prosocial behavior. (Liu Zhijun, 2003) Also, some research shows that ideal self and interpersonal self have significant correlation with the prosocial behavior (Yu Juan, 2006).

The research on the relations between interpersonal relationship and the internet altruistic behavior shows that, the level of social acceptance of individuals has significant correlation with the altruistic behavior conducted by him/her (Schonert-Reichl, 1999); adults with good social relations are more willing to conduct helping behavior (Dyer, 1980), while the individual tends to decrease altruistic behavior when the social support level of the individual is low (like being shoved) (Twenge et al., 2007). In this study, the results of study on correlation of inter-personal relation and internet altruistic behavior show that, inter-personal relation and internet altruistic behavior are of significant correlation $\left(\mathrm{r}=.408^{* *}, \mathrm{p}<.001\right)$, which is basically in compliance with previous study results.

The importance of interpersonal relationship is one characteristic of Chinese Confucian culture. The Chinese society does not to focus on the individual (namely, "personal standard") nor on the society (namely, "social standard”), but on the relationship (Liang Shuming, 2005). Relationship prevails and the influence of individuals' willing, emotions and demands on their social behavior is less than the influence of one person's relationship with others on it (He Youhui, 1998). The characteristics of Chinese interpersonal relationship is the key for the analysis of China's entire lifestyle (Sha Lianxiang, 2000), as well as for analyzing Internet altruistic behavior.

In the virtual cyber space, internet communication is motivated by college students' various needs, and the sense of security, brought by the isolation function and connecting function of network, facilitates the "familiar and intimate" interpersonal relationship between two strangers on the internet and induces more altruistic behaviors (Huang Houming, 2001). On the contrary, individuals with their demands unsatisfied and low interaction motivation are more likely to object to help others with virtual identities on the Internet and lead to more negative online behaviors.

\section{Conclusion}

Difference of total scores of internet altruistic behavior and its factor scores in students of different genders, grades and only child and child with siblings is not significant $(\mathrm{p}>.05)$. The dimensions of internet sharing and 
internet guidance have great difference in the sense of major $(\mathrm{p}<.05)$; and the scores of art students are higher than those of engineering students. Total scores of self concept have no significant correlation with the total scores of internet altruistic behavior and its factor scores; psychological self has a significant correlation with internet supporting; social self has a significant correlation with total score of internet altruistic behavior, internet supporting and internet reminding. Internet altruistic behavior has a significant correlation with inter-personal relation.

\section{Direction of the Future Research}

Sample size of this research is small, which leads to the limitation when conducting structural and statistical analysis on self concept, interpersonal relationship and altruistic behavior. In the future research, the sample size will be enlarged to check the effect of interpersonal relationship on Internet altruistic behaviors and whether self concept works as a medium. Interpersonal trust has better predicting effect on Internet altruistic behaviors. When the research on mechanism of interpersonal relationship related to Internet altruistic behavior is being carried on, that on interpersonal trust will be also added. Altruism is the highest level of prosocial behavior. Thus, to cultivate undergraduates' Internet altruistic behavior is helpful for individual undergraduate to develop a healthy Internet mentality and a harmonious interpersonal relationship, and it is also good for maintaining a good cyber order and creating a positive and civilized cyber space.

\section{Acknowledgements}

This paper is one of the stage achievements for soft science project (project No.: 122400450116) of Henan Science and Technology Department.

\section{References}

Cadenhead, A. C., \& Richman, C. L. (1996). The Effects of Interpersonal Personal Trust and Group Status on Prosocial and Aggressive Behaviors. Social Behavior and Personality, 24, 169-172.

Huang, H. M. (2001). Identity and Trust in Virtual Space. PhD Thesis of National Taiwan University, 2001.

Lei, L., \& Ma, X. H. (2012). The Relation between Teenagers’ Internet Moral Attitude and Deviant Behavior. Abstracts Collection of the 12th Session National Psychology Academic Conference.

Liang, S. M. (2005). Essence of Chinese Culture. Shanghai: People’s Publishing House.

Li, Y. F. (2008). The Study on Relation between Undergraduates' Moral Values and Self Concept and Altruistic Behavior [D]. Postgraduate Academic Thesis of Huazhong University of Science and Technology.

Lu, H. D. (2002). Social Psychology [M]. Changchun: Northeast Normal University Press.

Peng, Q. H., \& Fan, F. M. (2005). Internet Altruistic Behavior of Undergraduates and Its Revelation to Moral Education in Colleges and Universities [J]. Leading Journal of Ideological and Theoretical Education, 12, 49-51.

Staub, E. (1994) A Conception of the Determinants and Development of Altruism and Aggression: Motives, the Self, and Environment. In B. Puka (Ed.), Reaehing Out: Earing, Altruism, and Prosocial Behavior. New York \& London: Garland Publishing.

Shi, R. (2001) Social Psychology [M]. Shanghai: Shanghai People’s Publishing House.

Sober, E. (1988) What Is Evolution Altruism? Canada Journal of Philosophy, 14, 75-99.

Tu, W. S. (2001) Social Psychology Theory and Application [M]. Beijing: People’s Publishing House.

Van Lange, P. A. M., Van Vugt, M., Meertens, R. M., et al. (1998) A Social Dilemma Analysis of Commuting Preferences: The Roles of Social Value Orientation and Trust. Journal of Applied Social Psychology, 28, 796-820.

Wei, X. F., \& Pan, D. N. (2006) Discussion and Analysis on Social Exchange Behavior and Interpersonal Relationship. Social Sciences Review, 2006, 12.

Xue, D. Y. (2011) Investigation and Countermeasures on Higher Vocational Students’ Altruistic Behaviors and Interpersonal Relationships. Journal of Tianjin Institute of Financial and Commercial Management, 3, 13.

Yu, J. (2006) Middle School Students’ Prosocial Behavior and Its Related Research on Self-Concept. Postgraduate Academic Thesis of Northwest Normal University.

Zhao, H. H., Zhang, H. Y., et al. (2012) Undergraduates’ Trait Empathy and Internet Altruistic Behavior: Mediating Effect of Internet Social Support. Psychological Development and Education, 5, 478-484.

Zhang, Z. G. (1996) Social Psychology [M]. Beijing: People’s Education Press, 1996. 